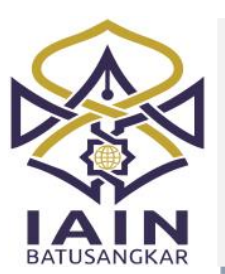

JURNAL TA'DIB, Vol 21 (2), 2018, (Juli-Desember)

ISSN : 1410-8208 (Print) 2580-2771 (Online)

Tersedia online di http://ecampus.iainbatusangkar.ac.id/ojs/index.php/takdib/index

\title{
PERANCANGAN E-MODULE PERAKITAN DAN INSTALASI PERSONAL KOMPUTER SEBAGAI MEDIA PEMBELAJARAN SISWA SMK
}

\section{Lidya Rahmi}

Institut Agama Islam Negeri Batusangkar, Sumatera Barat, Indonesia

E-mail: lidyarahmi@iainbatusangkar.ac.id

\begin{abstract}
Abstrak: The research discusses about the design of electronic module assembly and installating computer. The module was designed for assembling and installating computer content displayed in digital way, so this modul is very flexible and easy to be used. The content was displayed by video to make it easier to understand by the learners. The method used consists of several phases; analysis, design, coding and testing. The design used UML process and then was developed by Kvisoft Flip book maker. The result of this research shows how the assembly and installation module was easier to be used for the teacher and the students.
\end{abstract}

Kata Kunci: The learning module, electronic module, assembly, computer installation

\section{PENDAHULUAN}

$\mathrm{L}$ embaga pendidikan Sekolah Kejuruan mempersiapkan peserta didik untuk dapat bekerja dalam bidang keahliannya. Orientasi dari SMK adalah menyiapkan lulusan yang mampu langsung bekerja dan siap berkompetisi ke dunia usaha dan industri sesuai dengan bidang keahlian atau kompetensi yang dimilikinya. Hal ini sesuai dengan Peraturan Pemerintah RI nomor 19 tahun 2005 pasal 26 ayat 3 tentang bagaimana standar keahlian yang dimiliki lulusan pada sekolah kejuruan yaitu meningkatkan kemampuan, pengetahuan, kepribadian, akhlak mulia serta keahlian untuk mengembangkan kemampuan dan dapat melanjutkan pendidikan kejenjang yang lebih tinggi.

Untuk mencapai tujuan dari peraturan pemerintah tersebut sekolah harus membuat sistem pembelajaran yang baik dengan mengacu kepada kurikulum yang telah ditetapkan. Agar hal tersebut terlaksana perlu peningkatan kualitas pembelajaran di SMK. Elektronik modul merupakan sumber belajar yang dapat mempengaruhi terhadap peningkatan kualitas pembelajaran. Hal ini dikarenakan sumber belajar seharusnya dapat meningkatkan pemahaman siswa dalam menguasai teori pembelajaran yang akan menunjang pelaksanaan praktik dalam proses pembelajaran.

Modul elektronik adalah bagian dari sumber belajar berupa data, orang atau benda sehingga dapat dimanfaatkan sebagai media yang memudahkan siswa dalam proses pembelajaran. Sumber belajar itu meliputi pesan, orang, bahan, peralatan, teknik dan lingkungan/latar. Senada dengan hal tersebut, sumber belajar menurut Sadiman (2004:3) adalah sumber data dan informasi yang dikemas dan dikembangkan dalam bentuk modul, yang merupakan bahan ajar dirujuk dari kurikulum. Format yang digunakan adalah dalam bentuk cetakan, video, format perangkat lunak atau dapat 
berupa gabungan dari semuanya. Salah satu bentuk sumber belajar adalah modul pembelajaran. Modul pembelajaran digunakan sebagai panduan bagi siswa untuk melakukan pembelajaran secara mandiri dan lebih terarah. (Departemen Pendidikan Nasional, 2008:3) menyatakan sebagai berikut.

Elektronik modul adalah bahan pembelajaran yang dirancang untuk dapat digunakan siswa secara mandiri, karena di dalamnya memuat sebuah petunjuk untuk belajar sendiri. Artinya, siswa dapat memulai pembelajarannya secara sendiri meskipun tidak didampingi oleh tenaga pengajar. Modul dirancang selengkap mungkin, sehingga siswa dapat mengikuti prosedur pembelajaran sesuai dengan arahan yang diinginkan oleh guru.

Direktorat Tenaga Kependidikan, (2008:3) secara jelas menyatakan bahwa modul merupakan media pembelajaran yang memuat materi belajar, metode ajar, evaluasi pembelajaran yang menarik bagi siswa untuk mencapai kompetensi yang diharapkan. Modul sebagai sumber ajar dapat menggantikan proses pembelajaran tatap muka, sehingga dalam perancangan modul yang baik adalah menyampaikan sebuah materi ajar sehingga peserta didik merasa seperti mengalami pembelajaran langsung di kelas.

Penggunaan modul prooses pembelajaran di SMK membuat siswa mampu mempelajari materi pembelajaran dengan mandiri secara sistematis sehingga dapat mencapai kompetensi keahliann yang diharapkan(F S Irwansyah, I Lubab, 2017). Dalam hal ini Guru hanya berfungsi sebagai fasilitator dalam pembelajaran, membantu siswa untuk memahami tujuan pembelajaran dan melakukan evaluasi pembelajaran.
Informasi Teknologi saat ini berkembang dengan sangat cepat, dengan hal ini guru dapat melakukan eksperimen untuk mengembangkan modul pembelajaran. Berdasarkan hal itu didalam proses pembelajaran dapat mengggantikan peran guru saat memerikan sebuah pengetahuan, karena siswa dapat langsung mengakses beragam informasi yang tersedia di elektronik modul, baik melalui PC, laptop atau handphone. Sebahagian besar siswa saat ini lebih banyak memanfaatkan perkembangan TIK hanya untuk jejaring sosial seperti facebook, twitter, instagram dan situs youtube yang digunakan untuk sarana bersenang-senang bukan sarana pembelajaran. Sedangkan pemanfaatan perkembangan TIK hanya digunakan ketika membuat tugas sekolah. Jadi, siswa tidak memanfaatkan TIK sebagai media tambahan untuk pembelajaran .

Sesuai pengamatan yang telah dilakukan di SMK, pemahaman siswa terhadap materi pembelajaran dan interaksi pelajar dalam pembelajaran kurang efektif. Hal ini disebabkan oleh penggunaan modul pembelajaran. Modul pembelajaran yang digunakan selama tampak tidak menarik. Selain itu, modul yang ada saat ini tidak dilengkapi fitur multimedia seperti animasi, vidio dan juga suara(Nandya R. J. Hafsah, Dedi Rohendi, 2016)(Gall et al., 2006).

Upaya untuk mencapai kompetensi dan profesional seorang guru ada beberapa hal yang dapat dikembangkan. Salah satunya bentuk yang dapat dilakukan adalah mengembangan modul yang interaktif, sehingga siswa dapat lebih aktif dan kreatif dalam hal menggunakan software tertentu. sehingga menghasilkan modul yang dapat yang menarik bagi siswa. Modul yang sesuai untuk permasalahan tersebut dapat dikembangkan berupa modul elektronik. 
Beberapa penelitian telah dikembangkan oleh ahli sebelumnya, seperti modul $E$ Module mata pelajaran Kimia, E-Modul Berbasis Etnomatematika dan E-Module Mata Pelajaran IPA (Utami, Nugroho, Dwijayanti, \& Sukarno, 2018). Sehingga dengan modul elektronik tersebut dapat mengalihkan penggunaan TIK menjadi sumber pembelajaran.

Modul elektronik menurut Sugianto, dkk (2013:110-116) merupakan media pembelajaran mandiri dengan tujuan mencapai kompetensi pembelajaran yang diharapkan yang dikemas dalam bentuk elektronik terdiri dari : animasi, audio, navigasi sehingga menjadikan siswa lebih interaktif dengan aplikasi tersebut. Manfaatnya media elektronik adalah membuat proses pembelajaran lebih menarik, interaktif, yang dilakukan kapan dan dimana saja dilengkapi dengan pendukung multimedia(Nurmayanti, Bakri, \& Budi, 2015). Modul elektronik dijadikan sebagai sarana untuk infomasi dan komunikasi di dalam pembelajaran(Serevina \& Sari, 2018).

Proses pembelajaran pada kompetensi dasar menginstalasi personal komputer guru selalu menggunakan modul elektronik dengan format $p d f$ yang diberikan pada siswa sebagai modul tambahan dalam pembelajaran di dalam kelas dan pembelajaran mandiri siswa. Modul tersebut tidak dilengkapi video/audio untuk mendukung tampilan modulnya. Sehingga modul pembelajaran yang diberikan guru kurang menarik yang menyebabkan kurangnya interaksi siswa dalam pembelajaran. Selain itu, sedikitnya sumber belajar lainnya seperti buku pelajaran dan sarana laboratorium komputer, juga berdampak pada kurangnya minat dan pemahaman siswa terhadap materi
pembelajaran(Ahmad Jaenudin, Baedhowi, 2017).

Modul elektronik dikembangkan untuk meningkatkan pemahaman siswa dan minat belajar agar mereka berkompeten di bidangnya. Modul elektronik merupakan modul yang menggunakan teknologi yang dapat membantu siswa beradaptasi dengan perkembangan IT(Nurmayanti et al., 2015). Modul elektronik dilengkapi dengan teori praktek dan simulasi praktek pada materi konfigurasi BIOS sehingga siswa dapat belajar sendiri dengan modul elektronik dan dapat melakukan praktek dalam pembelajaran. Penyajian bahan pembelajaran yang dikemas dalam elektronik menjadi lebih praktis dan fleksibel terutama pada mata diklat Perakitan dan Instalasi Komputer. Elektronik modul pembelajaran ini mempermudah peran guru dalam memberikan informasi bagi peserta didik. Sementara bagi siswa modul ini akan membuat siswa lebih aktif dalam pembelajaran(Zulvianda, Hanum, \& Nazar, 2013).

\section{METODE PENELITIAN}

Penelitian ini menggunakan metode Sytem Development Life Cycle yaitu Waterfall (yogianto, 2010). Metode ini memiliki pendekatan seperti analisis bagi kebutuhan sistem lalu analis, desain coding, testing dan maintenance, pendekatan ini dilakukan secara sistematis mulai dari prosedur pertama sampai prosedur terakhir. Dalam merancang modul elektronik, menggunakan metode waterfall dilakukan pengumpulan informasi diantaranya kebutuhan fungsional dan non fungsional sehingga kita dapat melakukan desain modul elektronik(Ketut Krisnayuni, I Gede Mahendra Darmawiguna, 2015). 


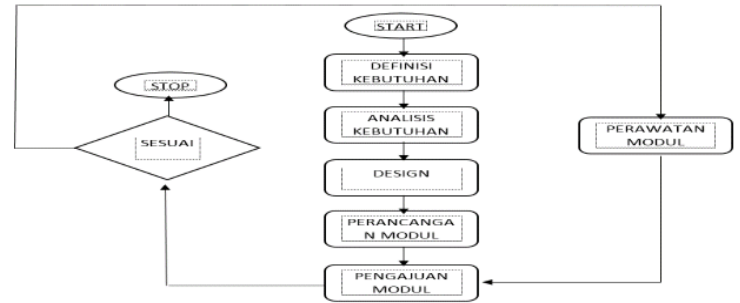

Gambar 1. Metode Waterfal (Sumber :

Dimodifikasi dari al Fatta, 2007)

Gambaran flowchart dalam penelitian ini sebagai berikut.

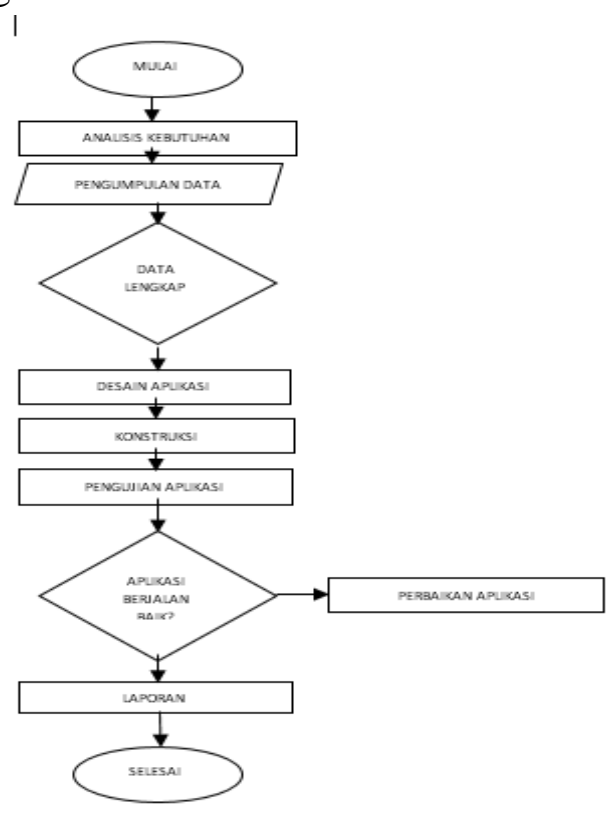

Gambar 2. Flowchart Penelitian

\section{HASIL DAN PEMBAHASAN}

Berikut hasil dari hasil pembuatan modul elektronik pembelajaran perakitan dan instalsi komputer

1. Halaman intro

Halaman intro merupakan halaman yang menggambarkan halaman depan atau cover dari modul elektronik. Gambaran halaman tampilan intro dilihat pada gambar dibawah ini.

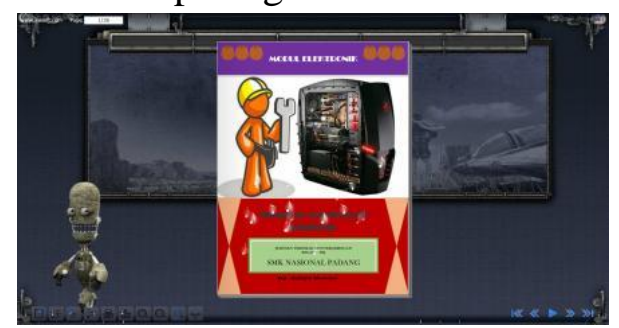

Gambar Halaman TampilanIntro
Halaman pengantar berisi judul modul dan juga video animasi 3D tentang modul Perakitan dan Instalasi. Gambaran Halaman pengantar dapat dilihat pada gambar berikut.

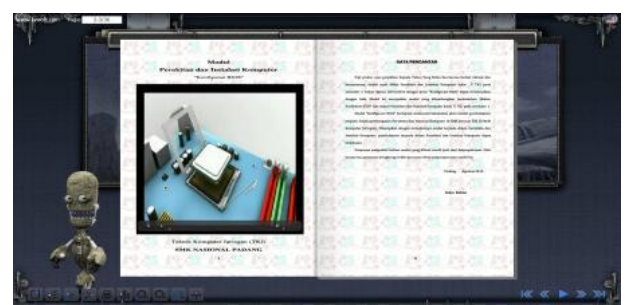

Gambar Halaman Pengantar

3. Halaman isi (pertemuan pertama)

Halaman isi (pertemuan pertama) merupakan halaman yang berisikan intro untuk materi pertemuan pertama. Didalam intro ini terdapat music, gambar dan animasi. Gambaran halaman isi (pertemuan pertama) dapat dilihat pada gambar di bawah ini:

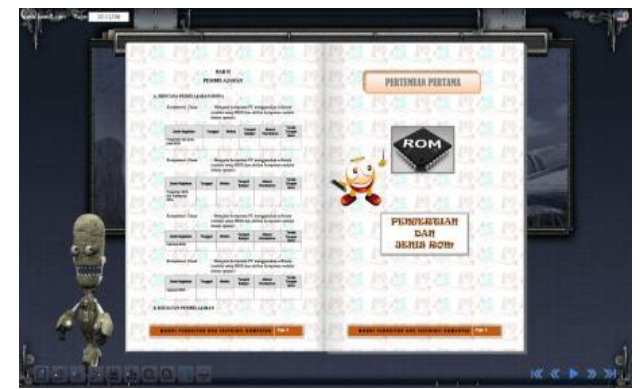

Gambar Halaman Isi (Pertemuan Pertama)

4. Halaman isi (pertemuan kedua)

Halaman isi (pertemuan kedua) merupakan halaman yang berisikan intro untuk materi pertemuan pertama. Di dalam intro ini terdapat musik, gambar dan animasi. Gambaran halaman isi (pertemuan kedua) dapat dilihat pada gambar berikut.

2. Halaman pengantar 


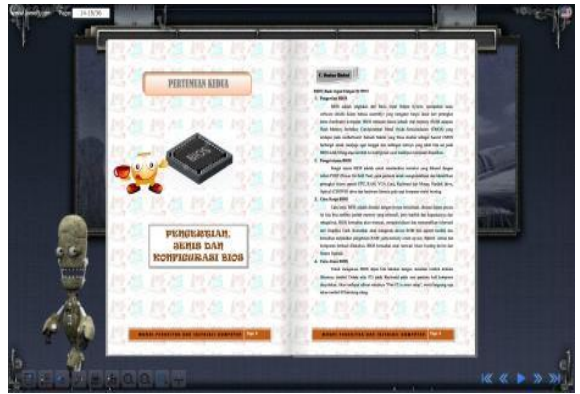

Gambar Halaman Isi (Pertemuan Kedua)

5. Halaman isi (pertemuan ketiga)

Halaman isi (pertemuan ketiga) merupakan halaman yang berisikan intro untuk materi pertemuan pertama. Di dalam intro ini terdapat musik, gambar dan animasi. Gambaran halaman isi (pertemuan ketiga) dapat dilihat pada gambar berikut.

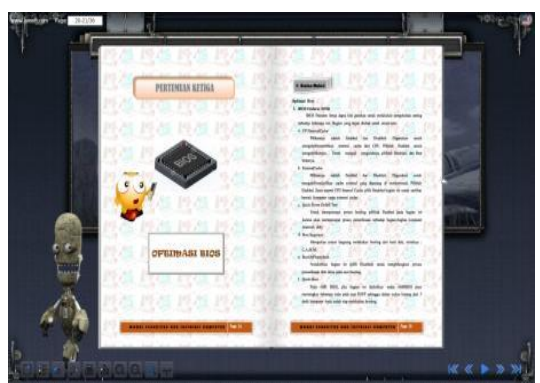

\section{Gambar Halaman Isi (Pertemuan Ketiga)}

6. Halaman isi (pertemuan keempat)

Halaman isi (pertemuan keempat) merupakan halaman yang berisikan intro untuk materi pertemuan pertama. Di dalam intro ini terdapat musik, gambar dan animasi. Gambaran halaman isi (pertemuan keempat) dapat dilihat pada gambar berikut.

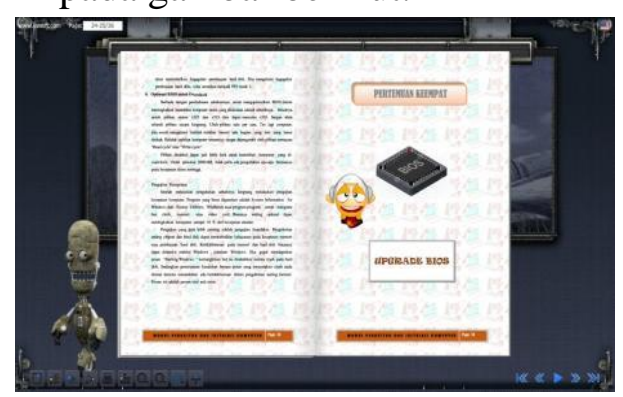

\section{Gambar Halaman Isi (Pertemuan Keempat)}

7. Halaman lampiran

Halaman lampiran berisi gambar-gambar dan video-vidio yang merupakan media yang membantu memperjelas isi materi dari modul. Gambaran halaman lampiran dapat dilihat pada gambar berikut.

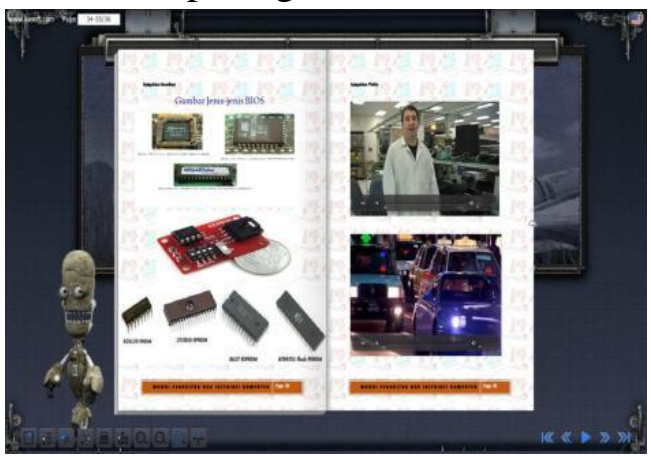

\section{Gambar Halaman Lampiran}

Pada masing-masing halaman terdapat lima tombol tampilan navigasi. Kegunaan dari tombol dapat dijelaskan sebagai berikut.

a) Tombol next. Tombol navigasi ini digunakan untuk link ke halaman selanjutnya.

b) Tombol back. Tombol navigasi ini digunakan untuk link ke halaman sebelumnya.

c) Tombol beginning. Tombol navigasi ini digunakan untuk link ke halaman awal.

d) Tombol end. Tombol navigasi ini digunakan untuk link ke halaman terakhir.

e) Tombol play. Tombol navigasi ini digunakan untuk menjalankan modul secara otomatis.

\section{KESIMPULAN DAN REKOMENDASI Kesimpulan}

Berdasarkan perancangan dan pembuatan modul elektronik perakitan dan instalasi komputer pembelajaran maka dapat disimpulkan sebagai berikut: (1) Modul 
elektronik pembelajaran perakitan dan instalasi komputer dikembangkan sesuai dengan proses analisis kebutuhan, perancangan desain, pembuatan dan pengujian terhadap modul yang telah yang sudah jadi. (2) Elektronik modul pembelajaran perakitan dan instalasi komputer bersifat praktis digunakan oleh guru dan siswa dalam proses pembelajaran

\section{Saran}

Disarankan kepada peneliti lain agar melakukan pengembangan hal yang serupa pada materi pembelajaran, baik pada mata pelajaran Perakitan dan Instalasi Komputer maupun pembelajaran lainnya dan disarankan untuk Kepala Sekolah SMK Nasional Padang perlu diadakannya alat bantu berupa speaker sehingga penggunaan modul elektronik dapat digunakan secara optimal.

\section{REFERENSI}

Ahmad Jaenudin, Baedhowi, T. M. (2017). The Effectiveness of the E-Module of Economics Learning on Problem-Based Learning used to Improve Students' Learning Outcomes Ahmad Jaenudin 1 , Baedhowi 1 , Tri Murwaningsih 11 , 158(Ictte), 30-36.

Al Fatta, Hanif. (2007). Analisis dan Perancangan Sistem Informasi. Yogyakarta : Andi Offset.

Depdikbud. 2003. Undang-Undang RI NO.20 Tahun 2003 tentang Sistem Pendidikan Nasional. Jakarta: Lemhanas.

Depdiknas. 2008. Penulisan Modul. Direktorat Tenaga Kependidikan.

Direktorat Tenaga Kependidikan. 2008. Penulisan Modul. Jakarta : Depdiknas.

F S Irwansyah, I Lubab, I. F. and M. A. R. (2017). Designing Interactive Electronic
Module in Chemistry Lessons.

Gall, M., D., Borg, W., R., ... P. (2006). Cap 14.pdf. Educational Research: An Introduction.

https://doi.org/10.7860/JCDR/2017/226 81.9972

Jogiyanto. (2010). Analisis dan Desain Sistem Informasi. Yogyakarta: Andi Offset.

Ketut Krisnayuni, I Gede Mahendra Darmawiguna, I. M. P. (2015). Pengembangan E-Modul Berbasis Model Project Based Learning Untuk Mata Pelajaran Video Editing, 4.

Majid, A. 2006. Perencanaan Pembelajaran. Bandung: PT. Remaja Rosdakarya.

Mulyasa, E. 2008. Kurikulum Berbasis Kompetensi. Bandung: PT. Remaja

Nandya R. J. Hafsah, Dedi Rohendi, P. (2016). Penerapan media pembelajaran modul elektronik untuk meningkatkan hasil belajar siswa pada mata pelajaran teknologi mekanik. Mechanical Engineering Education, 3(1), 106-112.

Nasution. 2005. Berbagai Pendekatan dalam Proses Belajar Mengajar. Jakarta: PT. Bumi Aksara.

Nurmayanti, F., Bakri, F., \& Budi, E. (2015). Pengembangan Modul Elektronik Fisika dengan Strategi PDEODE pada Pokok Bahasan Teori Kinetik Gas untuk Siswa Kelas XI SMA, 2015(Snips), 20132016.

Prastowo, A. 2012. Panduan Kreatif Membuat Bahan Ajar Inovatif. Yogyakarta: Diva Press.

Sadiman, Arif S. 2011. Media Pembelajaran: Pengertian, pengembangan dan Pemanfaatannya. Jakarta: PT. Grafindo Persada.

Serevina, V., \& Sari, I. J. (2018). Development of E-Module Based on Problem Based Learning ( PBL ) on 
Heat and Temperature to Improve Student' s Science Process Skill, 17(3), 26-36.

Sudjana, Nana. 2005. Teknologi Pengajaran. Bandung: Remaja Rosdakarya.

Sugianto, Dony dkk. 2013. Modul Virtual:Multimedia FlipBook Dasar Teknologi Digital. Jurnal INVOTEC, Vol. IX No.2Agustus 2013 p.110-116

Susilana, Rudi dan Cepi Riyana. 2008. Media Pembelajaran : Hakikat, pengembangan, pemanfaatan dan penilaian. Bandung: CV Wacana Prima

Utami, R. E., Nugroho, A. A., Dwijayanti, I.,
\& Sukarno, A. (2018). Pengembangan E-Modul Berbasis Etnomatematika Untuk Meningkatkan Kemampuan Pemecahan Masalah. Jurnal Nasional Pendidikan Matematika, 2(2), 268-283.

Wahono, R. S. 2006. romisatriawahono.net. Retrieved 09 19, 2013, fromromisatriawahono.net: http://romisatriawahono.net/2006/06 /21/aspek-dan-kriteria-penilaianmedia pembelajaran/

Zulvianda, H., Hanum, L., \& Nazar, M. (2013). Pengembangan E-Module Kimia SMA Pada Materi Larutan Elektrolit dan Non Elektrolit. Electronic Module atau Modul, 1(3), 916.

\section{Article Metadata:}

Rahmi. L. (2018). Designing E-Module Assembling and Installation of Personal Computers as Media of Instruction for Vocational School Students. Ta'dib, 21 (2), 105-112 http://dx.doi.org/10.31958/jt.v21i2.1190

Keywords: The learning module, electronic module, assembly, computer installation Coresponding author: Lidya Rahmi, IAIN Batusangkar, lidyarahmi@iainbatusangkar.ac.id 